\title{
OS PRIMEIROS ANOS DA RODRIGUÉSIA - 1935-1938: EM BUSCA DE UMA NOVA COMUNICAÇÃo CIENTÍFICA
}

Begonha Bediaga*

\section{RESUMO}

(Os primeiros anos da Rodriguésia - 1935-1938: Em busca de uma nova comunicação científica) Buscamos analisar os três primeiros anos do periódico científico Rodriguésia, publicado desde 1935. Essa primeira fase referese ao período em que a revista foi editada pelo Instituto de Biologia Vegetal, Jardim Botânico e Estação Biológica de Itatiaia e tinha uma proposta de alcançar um público mais amplo que a divulgação entre pares e abranger um escopo além da taxonomia botânica, como a entomologia agrícola, fitopatologia, genética e ecologia agrícola.

Palavras-chave: Rodriguésia, história de periódico cientifico, história das ciências naturais, história do Jardim Botânico do Rio de Janeiro, disseminação científica, difusão científica.

\section{Abstract}

(The first years of Rodriguésia - 1935-1938: Searching for a new science communication) We analyzed the first three years of the scientific journal Rodriguésia that is being published since 1935. During this period, the journal was edited by the Instituto de Biologia Vegetal, Jardim Botânico and Estação Biológica de Itatiaia. It had the purpose to reach other people over the scientific community including areas other than the Taxonomic Botany, such as Agricultural Entomology, Phytopatology, Genetics, and Agricultural Ecology. Key-words: Rodriguésia, history of Botanical Garden of Rio de Janeiro, scientific periodical, natural science, science dissemination, science communication.

\section{INTRODUÇão}

A Rodriguésia completa 70 anos neste ano. São poucos os periódicos científicos brasileiros que conseguiram resistir durante "longo" período, o que, naturalmente, nos instiga a refletir sobre sua trajetória. Entretanto, iremos analisar apenas os três primeiros anos da Rodriguésia - 1935 a 1938 - os quais correspondem aos onze primeiros números editados.

A escolha desse tempo histórico em que iremos nos deter se justifica por ter sido o período da primeira fase da revista. Nessa época, a Rodriguésia era uma publicação do Instituto de Biologia Vegetal, Jardim Botânico e Estação Biológica de Itatiaia. O escopo editorial da revista era mais abrangente, pois buscava também atingir o público leigo. Além de artigos de botânica também abrangia outras áreas, como entomologia, fitopatologia, genética e ecologia agrícola.

Em 1938, mudanças administrativas no Ministério da Agricultura ocasionaram a extinção do Instituto de Biologia Vegetal e o Jardim Botânico do Rio de Janeiro passou a ser subordinado ao Serviço Florestal, o que veio a interferir diretamente na Rodriguésia. Isto ocasionou a primeira suspensão na sua periodicidade dentre as inúmeras que ocorreram em épocas distintas e por motivos diversos ao longo de sua existência. ${ }^{1}$

Para nos auxiliar a compreender a inserção da Rodriguésia na comunidade científica botânica, procuramos identificar quais foram os principais periódicos científicos brasileiros que publicavam resultados de pesquisas botânicas no período anterior a 1935. Além disso, buscamos inserir a criação da Rodriguésia no contexto político de então, através de uma breve análise da década de 1930 no Brasil e das possíveis influências no escopo editorial da revista decorrentes das mudanças administrativas efetuadas na estrutura do Jardim Botânico.

Adotamos as definições fornecidas pela área da ciência da informação para disseminação científica e divulgação científica. A

\footnotetext{
${ }^{1}$ Segundo levantamento da Biblioteca Barbosa Rodrigues do JBRJ, nos 70 anos de existência da Rodriguésia não houve publicação em 17 anos intercalados, sendo que as décadas de 1960 e 1970 foram as com maior interrupção.
}

Artigo recebido em 02/2005. Aceito para publicação em 08/2005.

*Historiadora. Instituto de Pesquisas Jardim Botânico do Rio de Janeiro. Rua Pacheco Leão, 22460-030, Rio de Janeiro, RJ, begonha@jbrj.gov.br 
primeira é colocada como a difusão para especialistas da mesma área de conhecimento científico ou áreas afins. A segunda busca atingir um público não especialista, sendo também denominada vulgarização e popularização científica (Loureiro 2000). Utilizaremos as expressões revistas científicas e periódicos científicos como tendo significados idênticos.

\section{Publicação na área da botânica antes da Rodriguésia}

Os primeiros periódicos científicos datam do século XVII na Europa. No entanto, somente no século XIX passaram a ter uma importância maior para a comunidade científica. O prestígio adquirido deveu-se, primeiramente, à necessidade de reivindicar a prioridade da descoberta, da observação ou do experimento, fundamental para garantir o reconhecimento da autoria e evitar plágio. As revistas tinham a vantagem de serem editadas com mais rapidez e com custo bem menor que os livros (Stumpf 1996).

Os periódicos vieram a possibilitar uma publicação parcial das pesquisas, sem exigir a obra completa, como ocorria com os livros. Essa publicação em partes ocasionou a quase inevitável exigência em se manter a periodicidade, de maneira que se pudesse acompanhar a evolução das pesquisas e que as contribuições ou críticas se fizessem de forma mais rápida, através de novos fascículos. O não cumprimento dessa condição não excluía uma publicação de ser um periódico científico. No entanto, as revistas que logravam manter periodicidade com prazo predeterminado passaram a gozar de maior credibilidade junto aos cientistas.

O trabalho científico se caracteriza pelo acúmulo de conhecimentos, por meio das informações derivadas das pesquisas elaboradas por outros cientistas. Desde o século XIX, os autores e leitores das publicações científicas buscaram o reconhecimento pelos pares e também exerceram uma vigilância constante sobre a contribuição de cada pesquisa para os trabalhos científicos, assim ampliando a importância da citação da fonte de onde foram retiradas as informações, para que não fossem omitidos ou desfigurados trabalhos alheios. As revistas que publicavam artigos com essa exigência completa ganhavam notoriedade e ampliavam seu número de leitores (Martins 2003).

Nos periódicos do século XIX e início do XXos responsáveis pelas revistas (hoje chamados editores) não exigiam ineditismo. Era comum a prática de publicação simultânea em várias revistas, das quais inclusive constavam traduções de artigos publicados em outras revistas (Meadows 1999). Essa era uma forma encontrada para ampliar o número de leitores, devido às dificuldades que existiam para se ter acesso às publicações. Com o crescimento das permutas entre os periódicos e ampliação das bibliotecas e do número de assinantes de periódicos, algumas exigências foram criadas, entre as quais a de se publicar apenas artigos originais estabelecendose um diferencial que reve-lava maior qualidade entre os periódicos científicos.

Segundo estudos feitos para conhecer as formas de comunicação entre os botânicos, as revistas científicas nacionais aparecem "como o principal canal de comunicação dos botânicos brasileiros, com predominância em periódicos editados no Brasil" (Nogueira 2000).

Do universo de 80 periódicos científicos brasileiros atualmente indexados na área de botânica, ${ }^{2}$ para análise neste artigo selecionamos as revistas, de acordo com o seguinte critério: serem publicações anteriores a 1935, com sobrevida maior do que cinco anos e conterem artigos de botânica com regularidade. Resultaram três publicações: ${ }^{3}$ Archivos do Museu Nacional, Boletim do Museu Paraense

${ }^{2}$ Segundo o Catálogo Coletivo Nacional de Public ações Seriadas $(\mathrm{CCN})$, coordenado pelo Instituto Brasileiro de Informação em Ciência e Tecnologia (IBICT) em julho de 2005. Ressaltamos que essa listagem é considerada a mais completa e contém periódicos que não são mais publicados.

${ }^{3} \mathrm{~A}$ revista do Museu Paulista teve seu primeiro número publicado em 1895. Apesar de ser considerado pela CCN como periódico da área de botânica, verificamos que sua publicação esteve muito mais voltada para a zoologia. A botânica teve inexpressiva participação na totalidade dos artigos. Em estudo elaborado por M. M. Lopes (ibidem) entre os 23 primeiros volumes, a autora mostra que, de um total de 304 artigos, nove eram de botânica e 236 de zoologia. Para fins do estudo proposto, não iremos analisar esse periódico. 
de História Natural e Etnografia e Archivos do Jardim Botânico do Rio de Janeiro.

No Brasil, o início do processo de publicação de revistas científicas, na área das ciências naturais, somente ocorreu de forma sistemática a partir da criação do Archivos do Museu Nacional em 1876. Era dividido inicialmente em três seções: a primeira de antropologia, zoologia geral e aplicada e paleontologia animal; a segunda estava voltada para botânica geral e aplicada e paleontologia vegetal; a terceira tratava de assuntos de ciências físicas, como mineralogia, geologia e paleontologia. Sobre os primeiros 24 anos do Archivos do Museu Nacional - 1876 a 1930 —, a antropóloga L. M. Schwarcz (1993) afirma que o periódico, apesar da ampla gama de pesquisas que eram desenvolvidas no Museu Nacional, tinha uma preponderância maior de artigos referentes às ciências naturais, com cerca de $78 \%$, sendo que a zoologia contava com o dobro dos demais artigos publicados. Entre 1901 e 1915, apenas três artigos da área da botânica foram publicados, contra 23 da zoologia (Schwarcz 1993). Essa ausência de artigos em botânica na principal revista científica do Rio de Janeiro revelava parte da motivação que levou o Jardim Botânico a criar sua própria revista em 1915, Archivos do Jardim Botânico.

Cerca de 800 exemplares do Archivos do Museu Nacional eram enviados para instituições congêneres, museus e bibliotecas que, por sua vez, enviavam, em troca, muitos dos periódicos que auxiliaram no en grandecimento do atual acervo da biblioteca do Museu Nacional. O então diretor do Museu Nacional, Ladislau Neto, compreendia a necessidade de entrar nesse circuito de permutas de periódicos como forma de inserir as pesquisas brasileiras no cenário internacional (Lopes 1997).

O grande desafio naquele momento, para Ladislau Neto, foi manter a periodicidade do Archivos do Museu Nacional principalmente devido à exigência dos meios acadêmicos da Europa e dos EUA. Os empecilhos para um periódico científico cumprir seus compromissos eram muito grandes. Em geral, giravam em torno da falta de verbas e da carência de pessoal. Ladislau Neto, cientista com inúmeros trabalhos publicados, confirmava esses problemas e dizia que "entre todos seus afazeres no Museu Nacional, a revista do Museu era o que lhe tinha exigido maior atenção e cuidados" (Lopes 1995).

Outro periódico relevante na publicação de artigos referentes à botânica no período anterior a 1935 foi o Boletim do Museu Paraense de História Natural e Etnografia. ${ }^{4}$ A publicação foi iniciada com a posse de Emílio Goeldi na direção do Museu. O cientista, tendo se demitido do Museu Nacional, buscou imprimir na nova casa um caráter diferente daquele da instituição que deixara. Seguindo as instituições congêneres européias, mostrava claro empenho em acompanhar as pesquisas e os interesses dos naturalistas europeus e norte-americanos, o que se traduziu em contratações de estrangeiros para trabalhar no museu paraense, como Jacques Hubert e Adolpho Ducke, ambos com destaque na história botânica brasileira do século XX.

O primeiro número do Boletim foi editado em 1896 e correspondia aos anos de 1894 a 1896, englobando os fascículos de 1 a 4. No editorial do primeiro volume, a revista explicava que: "Não toma compromisso algum com a periodicidade de seu aparecimento... Os intervalos serão logicamente determinados pelo tempo que nos deixarem as outras ocupações museares [sic] e pelo material que nos afluir." revela a importância dada no século XIX à periodicidade das revistas científicas.

Mais adiante, esse mesmo editorial expressava a intenção de publicar, principalmente, ensaios referentes a pesquisas na região da amazônia, o que acarretou uma

\footnotetext{
${ }^{4}$ A publicação apenas mudou de nome para Boletim do Museu Paraense Emilio Goeldi a partir de 1933, mantendo até hoje o mesmo título.

${ }^{5}$ Boletim do Museu Paraense de His tória Natural e Etnografia. Tomo I - fascículo 1.
} 
restrição de espaço para os botânicos que estudavam outras formações vegetacionais brasileiras.

Assim como ocorria no Archivos do $\mathrm{Mu}$ seu Nacional, o Boletim do Museu Paraense teve nos estudos dos naturalistas a origem de grande parte dos artigos publicados nos cinqüenta primeiros anos, com a zoologia representando o maior número de artigos (48\%), seguido da botânica (36\%) e da geologia (10\%) (Schwarcz 1993).

O Boletim do Museu Paraense introduziu uma inovação ao publicar no mesmo periódico as partes administrativa e científica da instituição. Na primeira, eram tratados os assuntos de ordem interna do Museu, como notícias, regulamentos, necrológicos e relatórios de atividades. Na segunda parte encontravamse os relatos de excursões científicas, biografias de naturalistas e os artigos científicos produzidos pelos pesquisadores. Anos depois, a Rodriguésia assumiu um formato semelhante ao publicar as atividades do Jardim Botânico do Rio de Janeiro juntamente com os trabalhos científicos.

O Archivos do Jardim Botânico foi criado em 1915, no primeiro ano da gestão de Pacheco Leão. ${ }^{6}$ No breve editorial de apresentação da revista, o diretor do Jardim Botânico justificou sua criação como forma de dar "publicidade" aos trabalhos executados nos laboratórios e ao desenvolvimento do arboreto e do herbário da instituição. Acrescentou que a taxonomia deveria ser o assunto "primordial" da revista, que se encontrava aberta para receber artigos de especialistas externos à instituição.

Chama atenção a excelente qualidade gráfica da apresentação do Archivos do Jardim Botânico, desde sua criação até 1935, materializada pela alta definição na reprodução

\footnotetext{
${ }^{6}$ Antonio Pacheco Leão (1872-1931) foi sócio efetivo da seção de Ciências Biológicas da Academia Brasileira de Ciências desde 1916 (ano de sua fundação) e diretor do Jardim Botânico do Rio de Janeiro entre 1915 e 1931. Lutou pela obrigatoriedade da vacinação com o sanitarista Oswaldo Cruz no início do século 20.
}

das estampas, que eram impressas em papelcartão com tamanho maior do papel utilizado para o texto em si. Esse apuro no acabamento confirma a importância dada à taxonomia, uma vez que as ilustrações botânicas sempre foram fundamentais para a diagnose e descrição de forma a subsidiar a identificação dos táxons.

Compreender o escopo editorial do Archivos do Jardim Botânico nos leva a entender parte das motivações que resultaram na criação da Rodriguésia. Apesar de ter sido o primeiro periódico com artigos exclusivamente de botânica no Brasil, não encontramos em nossas pesquisas nenhuma referência à criação do Archivos do Jardim Botânico. A ênfase dada na sistemática possivelmente restringiu a busca de parte da comunidade botânica pelo Archivos do Jardim Botânico e indica um dos motivos para ausência de estudos e menções ao periódico em trabalhos de outras áreas do conhecimento.

Desde sua criação, o Archivos do Jardim Botânico enfrentou problemas para manter a periodicidade. ${ }^{7}$ No segundo número, em 1917, Löefgren, ${ }^{8}$ ao justificar a razão pela qual no seu artigo constassem os dois últimos anos das observações meteorológicas no Jardim Botânico, manifestou seu descontentamento por "não ter sido possível a publicação no último ano" sem indicar as causas, destarte afirmando indiretamente que a publicação deveria ter sido feita. A partir do terceiro volume, publicado em 1922, informou o editorial que "O Archivos

${ }^{7}$ Foram publicados oito volumes do Archivos do Jardim Botânico do Rio de Janeiro até 1935, a saber: 1915, 1917, 1922, 1925, 1930, 1933, 1934 e 1935. Os volumes de 1934 e 1935 foram publicados com o título de Archivos do Instituto de Biologia Vegetal.

${ }^{8}$ Alberto Löefgren, 1854-1918. Sueco, veio trabalhar no Brasil em 1874 executando diversas pesquisas no Museu Goeldi. Em 1913, foi contratado para exercer a função de chefe da seção de Botânica e Fisiologia Vegetal no Jardim Botânico do Rio de Janeiro. Apesar de não termos a informação do papel dos membros do conselho editorial do Archivos, percebe-se através da leitura dos primeiros números, percebe-se que Löefgren exerceu um papel no Archivos semelhante ao que hoje chamamos de editor. 
serão publicados em época não determinada...". A partir de então essa determinação se perpetuou até os dias de hoje, quando constatamos que o último número publicado foi o volume XXXIII, em 1995.

Até 1933 o Archivos do Jardim Botânico seguiu os objetivos definidos pelo primeiro editorial, de proporcionar publicações principalmente na área da taxonomia. Os naturalistas que pertenciam ao quadro funcional do Jardim Botânico, como A. Ducke, A. Löefgren, M. Kulhman, P. Campos Porto e F. Silveira, contribuíram com 27 artigos, dentre os 34 referentes aos seis primeiros volumes (1915-1933) assim corroborando ter esse periódico servido, principalmente, como repositório dos trabalhos realizados pelos pesquisadores da instituição.

A comunicação do Archivos do Jardim Botânico do Rio de Janeiro era claramente direcionada para um público muito específico de botânicos. Um dos indicadores dessa afirmação é a apresentação de diversos artigos publicados em alemão e francês, além de um conteúdo muito específico na área $\mathrm{da}$ sistemática. Além disso, era bastante comum que os artigos fossem muito extensos e ocupassem quase todo o conteúdo de uma publicação como exemplo, o artigo de A. Ducke: "Plantes nouvelles ou peu connues de la règion amazonienne - II parte", com 281 páginas.

Em 1934, houve uma mudança administrativa no Ministério da Agricultura, com a criação do Instituto de Biologia Vegetal. Dessa mudança decorreu a fusão do Archivos do Jardim Botânico com o Boletim do Instituto Biológico de Defesa Agrícola para formar o Archivos do Instituto de Biologia Vegetal. As principais modificações verificaram-se no escopo editorial, ampliando-se a área de abrangência para além da sistemática. $\mathrm{O}$ editorial desse primeiro número informava que ao Instituto de Biologia Vegetal "compete, de modo precípuo, investigar os fenômenos pertinentes à biologia, orientando, na medida do possível, suas pesquisas para assuntos mediata ou diretamente relacionados com a expansão, defesa e racionalização da agricultura brasileira". No entanto, essa nova orientação não resultou em mudanças significativas para a constituição do Archivos, possivelmente pela curta duração do Instituto de Biologia Vegetal.

\section{O Jardim Botânico do Rio de Janeiro na década de 1930}

Na década em análise, o JBRJ era subordinado ao Ministério da Agricultura e fazia parte do Instituto de Biologia Vegetal, órgão que funcionava nas dependências do próprio Jardim juntamente com a administração da Estação Biológica de Itatiaia.

No seu primeiro número, a Rodriguésia se apresentou como uma revista do Instituto de Biologia Vegetal, do Jardim Botânico e da Estação Biológica de Itatiaia (Fig. 1). Da

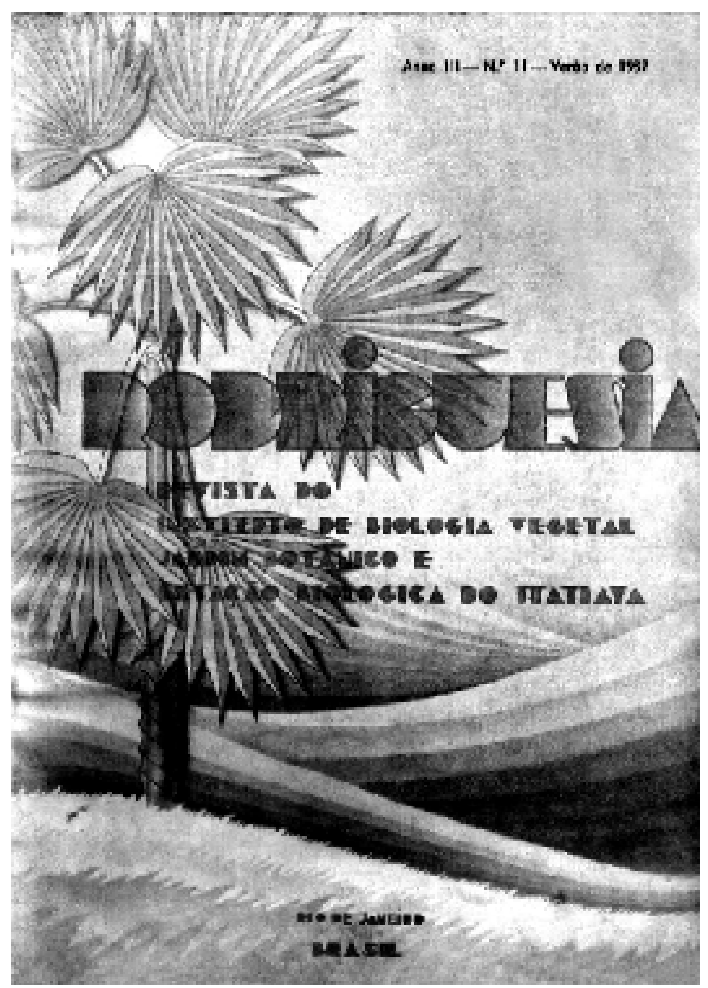

Figura 1 - Ilustração utilizada na antiga capa da Rodriguésia elaborada para o lançamento da revista. A estilização da carnaubeira - Copernicia prunifera (Mill.) H. E. Moore - , do artista C. Lacerda, revela o traçado modernista da época, em concordância com o movimento cultural que es tava em curso no Brasil. 
sua leitura podemos perceber que o Jardim Botânico foi o principal e quase único assunto das seções de Noticiários e Biblioteca. Paulo Campos Porto na Rodriguésia 1(3), 1936, então diretor do Instituto de Biologia Vegetal, comentando sobre o falecimento de um Ministro da Agricultura que havia ajudado muito o Jardim Botânico, referiu-se: "aos importantes melhoramentos que in troduziu no Jardim Botânico (construção da sua sede), hoje Instituto de Biologia Vegetal...". Essa observação nos indica que o Instituto de Biologia Vegetal englobava o Jardim Botânico e a Estação Biológica de Itatiaia. No entanto, a capa da Rodriguésia daquela época ao estampar os três "órgãos" separadamente, indican do que os três "órgãos", confundemse nos objetivos e subordinações institucionais.

Contudo, o que mais importa ressaltar na criação do Instituto de Biologia Vegetal foi a extensão das pesquisas para as novas áreas pelas quais a recém-criada instituição, sob o comando de P. Campos Porto, passou a se responsabilizar. $\mathrm{Na}$ estrutura organizacional que identificamos ao pesquisar os relatórios ministeriais, consta que o Departamento Nacional da Produção Vegetal do Ministério da Agricultura tinha como subordinado o Instituto de Biologia Vegetal, no qual estava incluído o Jardim Botânico - nele, por sua vez, incluída a Estação Biológica de Itatiaia. Além do Jardim Botânico, o Instituto de Biologia Vegetal contava com as seções de botânica, entomologia agrícola, fitopatologia, genética e ecologia agrícola.

Em 1938, mudanças administrativas ocorreram no Ministério da Agricultura: o Instituto de Biologia Vegetal foi extinto e tanto o Jardim Botânico quanto o recém-criado Parque Nacional do Itatiaia, passaram a ser subordinados ao novo Serviço Florestal. Esse novo órgão integrou as seções de botânica do antigo Instituto de Biologia Vegetal — da qual o Jardim Botânico ficou responsável —, além das áreas de silvicultura, tecnologia de produtos florestais e de parques nacionais. Percebe-se a grande mudança dos rumos adotados, o que ocasionou, nesse mesmo ano, a interrupção da publicação da Rodriguésia. Tal interrupção persistiu até a revista ser assumida pelo novo órgão, que manteve o seu nome original mas mudou a sua orientação editorial, passando a atribuir com maior ênfase à anatomia vegetal, silvicultura e dendrologia e orientação da produção agrícola.

As mudanças ocorridas no Jardim Botânico, do período da criação da Rodriguésia até sua incorporação pelo Serviço Florestal, teve o importante papel do diretor do Instituto de Biologia Vegetal e editor-chefe da Rodriguésia, Paulo Campos Porto. Nomeado natu-ralista do Jardim Botânico em 1914, foi superintendente da Estação Biológica de Itatiaia de 1929 a 1933 e dirigente do Instituto de Biologia Vegetal, de 1934 a 1938. Teve uma atuação decisiva na elaboração do projeto de criação do Parque Nacional de Itatiaia e, posteriormente, foi responsável pela criação do Parque Nacional do Monte Pascoal, na Bahia. Na sua trajetória profissional, demonstrou especial interesse na conservação da natureza, além de uma expressiva produção de artigos científicos e, principalmente, uma especial habilidade e competência ao ocupar cargos político-administrativos, o que lhe conferiu autoridade e liderança entre os profissionais da área. Estabeleceu uma aproximação com Getúlio Vargas, então Presidente da República, demonstrada pelas suas diversas visitas à instituição e pelo apoio recebido para a criação do Parque Nacional do Itatiaia. Ademais, circulou com muita aceitação na elite social, angariando patrocinadores para o Jardim Botânico. Confirmando sua confiança em Campos Porto, Getúlio o nomeou novamente quando assumiu a Presidência da República, em 1950. Além dos méritos pessoais de Campos Porto, um dado na sua biografia o auxiliou tanto nos contatos políticos como na respeitabilidade obtida juntamente à comu- 
nidade científica: era neto ${ }^{9}$ de Barbosa Rodrigues, que, como veremos mais adiante, teve uma importante atuação científica e administrativa e foi homenageado ao ter o nome escolhido para a Rodriguésia.

\section{Rodriguésia}

Para melhor entendimento do projeto que conduziu a criação da Rodriguésia, é necessário entender as circunstâncias que estavam em jogo no país no período e que influenciaram tanto o escopo editorial como no conteúdo dos artigos.

A Rodriguésia foi criada em 1935, cinco anos após início do governo de Getúlio Vargas. O novo governo, inspirado pela ideologia antiliberal, orientou-se por um projeto político nacionalista e centralizador empolgando grande parte dos segmentos sociais e inaugurando uma nova era no Brasil. Novos espaços foram abertos para a reestruturação e o controle do Estado. Diversos intelectuais, de diferentes matizes ideológicas, deram apoio, inicialmente, ao novo projeto. Com a ampliação da burocracia estatal, ocuparam cargos na administração pública e influenciaram no sentido de buscar mudanças governamentais. Com apoio da imprensa, formaram uma corrente de opinião favorável a esse "novo" projeto para o Brasil.

A divulgação científica fazia parte dessa "nova" concepção de relações entre o governo e a população que "deveria ser educada". Um exemplo que elucida o investimento do estado para efetivação dessa política foi a criação da Revista Nacional de Educação. Editada entre 1932 e 1934 pelo

\footnotetext{
${ }^{9}$ Exis tem controvérsias se Paulo Campos Porto era ou não neto de Barbosa Rodrigues. Entretanto um recorte de jornalencontrado na biblioteca do JB parece colocar um ponto final nessa polêmica. Na reprodução do discurso de Campos Porto por ocasião de sua posse, em 1951, ao falar sobre a instituição que passa-ria a dirigir novamente, afirmou: “...Confunde-se no meu espírito a sua história, desde 1890 , com a da minha própria família, pois já então o meu ilustre avô, Barbosa Rodrigues e Joaquim Campos Porto, meu pai...”. Jornal do Brasil, 01/05/1951.
}

Museu Nacional, sob direção de Edgar Roquette-Pinto, financiada pelo Ministério da Educação e Saúde, teve uma importante repercussão na sociedade, com a expressiva tiragem, para a época, de 12.500 exemplares (Duarte, 2004). Tendo como proposta ser um "gesto educativo rigorosamente popular", contou com artigos assinados por diversos intelectuais e com a ativa colaboração dos cientistas do Museu Nacional, tanto na sua direção quanto na autoria de artigos. Tinha como objetivo popularizar o conhecimento científico em diversas áreas, como genética, zoologia, botânica, arqueologia, matemática. $\mathrm{Na}$ área das ciências naturais, a ênfase era na flora e fauna do Brasil, pois, argumentavam os editores da Revista Nacional de Educação, os livros didáticos não utilizavam exemplos da natureza brasileira e, por conseguinte, "nossas crianças" tinham referências somente da natureza européia. Havia a preocupação de marcar um discurso nacionalista, exaltando as nossas riquezas naturais.

A trajetória do Jardim Botânico e do Museu Nacional foi marcada por vínculos históricos que podem ser explicados, de forma sucinta, pelo fato de as duas instituições terem participado da política cultural e científica implantada por d. João VI e inauguradas em épocas muito próximas, com objetivos semelhantes em algumas áreas. Além disso, apesar do Jardim Botânico não ter sido criado com a proposta de ser um museu, tem em seu arboreto um espaço de museu, ${ }^{10}$ pois expõe o resultado de parte da sua atividade científica ao público com objetivos de pesquisa e de lazer desde 1819.

O Museu Nacional e o Jardim Botânico do Rio de Janeiro encontram nas ciências naturais, especialmente na botânica, a área de

\footnotetext{
${ }^{10} \mathrm{O}$ conceito de Museu é bastante complexo para discutirmos neste espaço. No entanto, a definição do dicionário Aurélio nos auxilia a compreender: "Qualquer estabelecimento permanente criado para conservar, estudar, valorizar pelos mais diversos modos, e sobretudo expor para deleite e educação do público, coleções de interesse artístico, histórico e técnico."
} 
interseção mais forte, sendo usual os cientistas dessas instituições trabalharem em pesquisas análogas e desenvolverem projetos em conjunto, de forma que é marcante a recíproca influência. A criação da Revista Nacional de Educação bem como o sucesso da sua linha editorial nos indicam ter havido uma influência dessa revista na criação e nos objetivos da Rodriguésia. Percebem-se semelh anças entre as duas, ao fazerem ambas um forte apelo para a importância de se conhecer a flora do Brasil e ao buscarem atingir um público leigo, através da difusão científica, além da comunicação entre os pares. Essa foi uma importante novidade para as duas instituições centenárias que, até então, buscavam em relação a seus respectivos periódicos científicos, principalmente serem aceitas pela comunidade científica internacional.

A Rodriguésia ao ser criada, apresentava uma estrutura editorial com cinco seções: a primeira chamava-se Trabalhos de Divulgação e Notas Prévias e era constituída por trabalhos em etapas iniciais de desenvolvimento, oferecendo a oportunidade de serem publicadas observações, hipóteses de pesquisa e pequenas notas, em um linguajar acessível ao leigo. Buscava dessa maneira incentivar os pesquisadores a tornarem públicos os resultados parciais de seus trabalhos, de maneira a iniciar um aprendizado para futuras publicações de artigos científicos mais elaborados. A segunda seção, chamada Nótulas Botânicas, apresentava curiosidades da botânica que eram de interesse geral como: florações da estação, identificações de árvores utilizadas em praças e ruas das cidades e, discorriam sobre assuntos considerados mais fastidiosos como as controvérsias na classificação de algumas espécies, utilizando um linguajar simples e de forma bastante abreviada. Percebe-se a preocupação que havia em dar transparência às atividades do Jardim Botânico do Rio de Janeiro na parte de Noticiários e Atividades Várias. Aqui os diversos cursos oferecidos, assim como breves resumos das atividades de cada seção da instituição, notas sobre as visitas ilustres ao Jardim Botânico e outros, eram divulgados traduzindo a orientação de oferecer à população condições de acompanhar e participar das atividades do JBRJ. À seção de Biblioteca era reservada para notícias sobre a inclusão de novas aquisições do acervo promovidas pelo médico e bibliotecário Pedro Vasco dos Santos, além das obras comentadas por especialistas. A seção de Relatórios era utilizada geralmente para a narrativa pormenorizada das atividades dos pesquisadores em excursão científica para documentação da flora brasileira através das coletas, buscando assim demonstrar que as atribuições do Jardim Botânico eram mais amplas, não se limitan do ao que a população tinha conhecimento ao passear no arboreto.

Ao analisarmos os primeiros números da Rodriguésia, é possível perceber que foi criada com objetivos ambiciosos, ao se propor publicar quatro números por ano e atingir um público além da comunidade científica. Também existia a preocupação em prestar contas à sociedade, como forma de justificar a existência de uma instituição dedicada a conhecer e divulgar a flora brasileira. Buscava ainda angariar recursos da sociedade civil, como podemos constatar ao ler essa frase que consta nos primeiros números: "O Jardim Botânico receberá em espécie, plantas, sementes, material para laboratório, livros, a fim de aumentar a sua eficiência" ou na palestra publicada na Rodriguésia: ${ }^{11}$ 'Em todos os países civilizados, a construção e conservação de obras tão formosas e bonitas como o Jardim Botânico, contam mais com a iniciativa generosa de particulares do que com a atenção e os auxílios oficiais".

O primeiro editorial deixa claro a preocupação em atingir um novo público ao discorrer sobre os trabalhos científicos que a

\footnotetext{
${ }^{11}$ Palestra (sem autoria) sobre a inundação que provocou uma tragédia nas instalações do Jardim Botânico, pronunciada na "Hora do Brasil", do Departamento de Propaganda do Ministério da Justiça e Negócios Interiores (Rodriguésia 1(4): 1).
} 
instituição produz e que são publicados em brochuras ou na outra revista científica, Archivos do Jardim Botânico. No entanto, ressalta, “(...) nem por is so as demais atividades do Instituto [refere-se ao Instituto de Biologia Vegetal] devem ficar desconhecidas dos interessados, apenas porque não se enquadram em publicações do tipo dos "Archivos"'. A nova publicação deveria conter "tudo quanto não couber nos moldes dos Archivos" ou seja, artigos científicos "mais leves" e, principalmente, divulgação das atividades dos órgãos que faziam parte da revista, além de levar conhecimento ao público leigo. Para fins da comunidade científica, o Archivos deveria continuar existindo com a sua antiga estrutura e escopo editorial.

A Rodriguésia apresentava frases em destaques localizadas entre as seções e repetidas, de forma idêntica, a cada novo número. Apesar de não conhecermos os autores, a leitura atenta das frases nos auxilia a compreender a linha editorial da revista, assim como qual era o público que almejava alcançar. Essas expressões deixavam transparecer a intenção de exaltar o Jardim Botânico como "único" depositário da flora brasileira, além de valorizar a natureza do país. Podemos perceber também o propósito de uma comunicação direta com o público:

"O Brasil possui a maior flora e, por isto, espera que todos concorram para o desenvolvimento do Jardim Botânico."

"O Brasil possui o melhor Jardim tropical do mundo. A colaboração do público contribuirá para conservar esse conceito."

"O Jardim Botânico do Rio de Janeiro aguarda o auxílio de todos os brasileiros, a fim de que possa constantemente elevar o nome que vem mantendo no mundo entre os estabelecimentos congêneres." "O Jardim Botânico receberá qualquer contribuição em espécie, plantas, sementes, material para laboratório, livros, a fim de aumentar a sua eficiência."
A valorização e difusão do Jardim Botânico do Rio de Janeiro como depositário da diversidade vegetal brasileira e sua importância científica podem ser destacadas em uma das frases que separam seções do periódico:

"O Jardim Botânico do Rio de Janeiro é um mostruário vivo e permanente da inigualável flora brasileira, exposto aos olhos maravilhados de nacionais e estrangeiros que nos visitam. A contribuição do público fará conhecida a flora regional dos Estados."

A missão institucional parecia estar contemplada em uma dessas frases: "O Jardim Botânico é um instituto para a ciência e para o povo." Verifica-se o compromisso da instituição com a ciência, imprimindo, contudo, o propósito de vincular o conhecimento científico ao serviço da população. Possivelmente, essa postura perante a sociedade tenha sido adotada pela primeira vezna história do Jardim Botânico, então com 127 anos de existência.

Outro elemento que nos auxilia a elucidar a história da Revista é o nome escolhido pelos seus idealizadores. Tratava-se de uma homenagem ao cientista que foi diretor do Jardim Botânico do Rio de Janeiro, João Barbosa Rodrigues. Os dados biográficos disponíveis mostram episódios da sua trajetória profissional que revelam a preocupação em marcar uma posição de defesa intransigente do desenvolvimento científico do país, ao expor, claramente, os obstáculos de se "fazer" ciência no Brasil, as dificuldades em pesquisar herbários, livros de referências etc. Divergia, de forma corajosa, da prioridade científica obtida por alguns cientistas estrangeiros enviados por países da Europa, acusando-os de usurpação na autoria de espécies novas (Sá 2001).

Barbosa Rodrigues talvez tenha sido o botânico do século XIX que mais enfrentou preconceitos de estrangeiros e brasileiros e não se poupou em divulgar a sua discordância, mostrando-se bastante polêmico. Na publi- 
cação anexa à sua obra Sertum Palmarum, Barbosa Rodrigues (1879) reivindicou a autoria da descrição de algumas palmeiras que estavam sendo publicadas como descritas pelo botânico inglês James Trail:

"O fato de o brasileiro viver longe dos focos da luzes, não implica ser ele besta de carga para os felizes que legislam na Europa. É novo, aceitem como aceitamos o que de lá nos vem, sem ser acompanhado de herbário".

Homenagear Barbosa Rodrigues revela uma forma encontrada pelos editores da Rodriguésia de laurear o trabalho científico e a postura política do pesquisador, que orientou sua carreira em busca da independência de pensamento. Produziu conhecimento além das ciências naturais, versando sobre diversos assuntos. Estudou geografia para entendimento da região e dos locais em que coletava as plantas e enfatizou a importância de se pesquisar os vegetais nas localidades de origem. No contato com os índios, estudou o idioma para compreender a nomenclatura indígena na classificação da flora, desenvolvendo pesquisas sobre a origem do nativo brasileiro, sempre buscando compreender e valorizar o saber indígena (Rodrigues 1905). Por essa postura, considerada de vanguarda para sua época, a Rodriguésia buscou reverenciar e, também, imortalizar o nome de Barbosa Rodrigues para a história das ciências no Brasil.

Consta do primeiro número da Rodriguésia um artigo de Fernando Rodrigues da Silveira sobre a história do Jardim Botânico do Rio de Janeiro. Podemos verificar que o texto é uma compilação do que Barbosa Rodrigues havia escrito em diversos trabalhos, principalmente no livro de comemoração do centenário da instituição (Rodrigues 1908). O autor afirma ser Barbosa Rodrigues "o verdadeiro criador do Jardim [Botânico do Rio de Janeiro]" (Rodriguésia 1(1) 1935), evitando discorrer sobre quase um século de existência da instituição, 1808-1889. Aliás, essa análise da história do Jardim Botânico foi corroborada por diversos autores, como o já citado Paulo Campos Porto, que, concordando, afirmou: “ $\mathrm{O}$ Jardim Botânico, digam o que disserem, é uma obra da República, exclusivamente, do Marechal Deodoro da Fonseca, embora tenha sido fundada pelo rei d. João VI..." (Rodriguésia 2(5) 1936). Entretanto devemos levar em conta que Barbosa Rodrigues foi o representante da recém proclamada república no Jardim Botânico e buscou desaprovar publicamente a administração anterior, ao assumir em 1890. Segundo suas próprias palavras: "Assim, era impossível considerarse o Jardim um estabelecimento científico sério, a contrastar com o título que levou de: Jardim Botânico" (Rodrigues 1908).

Para o legado da memória coletiva, Barbosa Rodrigues se apresenta até os dias atuais, de certa maneira como "o verdadeiro criador do Jardim Botânico”. Essa memória muito bem criada e esculpida pelo próprio Barbosa Rodrigues, foi confirmada pelo seu neto, Campos Porto, ao identificar seu avô como o "pioneiro" da ciência no Jardim Botânico do Rio de Janeiro. De certa forma, o neto objetivou também ser "pioneiro" na comunicação científica ao buscar dar publicidade ao que se produzia no Jardim Botânico, e para tanto utilizou como principal canal de propaganda institucional a Rodriguésia.

\section{Considerações Finais}

O projeto editorial da Rodriguésia passou por diversas modificações ao longo do tempo, excluindo-se algumas seções e enfatizando-se outras. A idéia original não teve continuidade e a Rodriguésia seguiu o caminho da maioria das revistas científicas, a comunicação exclusivamente entre os pares, ou, para utilizar o termo correto: a disseminação científica. Apenas a seção Noticiários resistiu durante longo tempo e tornou-se, atualmente, uma das principais fontes para subsídios àqueles que buscam informações sobre o passado do Jardim Botânico do Rio de Janeiro.

Interessante observar que em nenhum dos volumes analisados do Archivos do Jardim 
Botânico, depois chamados de Archivos do Instituto de Biologia Vegetal, foi mencionada a criação da Rodriguésia. Essa ausência corrobora, de certa forma, a análise que desenvolvemos neste artigo ao afirmar que a Rodriguésia, no período da sua criação, não tinha intersecção com o Archivos.

Para além do estudo empreendido, percebemos que a trajetória histórica da Rodriguésia durante seus 70 anos de existência, assumiu diferentes enfoques, com maior ou menor número de artigos nas áreas de botânica, dendrologia, agricultura, entomologia, genética, fitogeografia, ecologia e outros. Podemos assinalar paralelos na mudança dos escopos editoriais com a história administrativa do Jardim Botânico do Rio de Janeiro. A importância da análise dessas variações transforma o periódico em uma imprescindível fonte de informações para se compreender a história do Jardim Botânico, de 1935 aos dias atuais. O JBRJ tem uma trajetória de inúmeras oscilações na sua missão institucional, ocasionadas, dentre outras causas, pela subordinação a diversos órgãos da administração pública. Essas vinculações provocaram, em longo prazo, mudanças de linhas pesquisa, de acordo com os interesses do ministério do órgão a que estivesse atrelado, seja como diretoria, superintendência ou mesmo seção. Ea Rodriguésia espelhou essas mudanças direta ou indiretamente. No entanto, não se deve estabelecer uma relação causal imediata, ou melhor, mudanças administrativas na instituição não produziram transformações instantâneas no escopo do periódico, foram processos de adaptações da revista com a instituição que a financiava.

Infelizmente, não houve preocupação em constituir um arquivo com o material gerado na confecção da Rodriguésia. Documentos de grande valia foram eliminados, como os pareceres de especialistas sobre os artigos publicados, trabalhos que foram recusados para publicação, atas de reuniões da Comissão Editorial e outros. Não nos foi possível ter informação, por exemplo, sobre a qual área do conhecimento pertenciam os artigos recusados; se o número de trabalhos que afluíam para a revista era grande e outras questões mais, que poderiam ter auxiliado a elucidar melhor a análise do periódico. Com um olhar no futuro, vale lembrar que a guarda do acervo documental deve seguir as normas estipuladas pela Constituição brasileira, de forma a preservar a identidade dos autores no tempo necessário.

\section{REFERÊNCIAS Bibliográficas}

Duarte, R. H. 2004. Em todos os lares, o conforto moral da ciência e da arte: a revista Nacional de Educação e a divulgação científica no Brasil (19321934). História, Ciências, Saúde: Manguinhos 11(1): 33-56.

Fausto, B. 2001. História concisa do Brasil. Ed. Universidade de São Paulo, Imprensa Oficial do Estado, São Paulo, 324p.

Lopes, M. M. 1997. O Brasil descobre a pesquisa científica: os museus e as ciências naturais no século XIX. Ed. Hucitec, São Paulo, 369p.

Loureiro, J. M. M. 2000. Representação e museu científico: o instrutivo aparelho de hegemonia ou uma profana liturgia hegemônica. Tese apresentada ao curso de Doutorado. IBICT-UFRJ/ECO. Rio de Janeiro, 179p.

Martins, R. 2003. Do papel ao digital: a trajetória de duas revistas científicas brasileiras. Dissertação - IBICT-UFRJ/ECO, 175p.

Meadows, A. J. 1999. A comunicação científica. Ed. Briquet de Lemos/livros, Brasília, 269p.

Motoyama, S. 2004. Prelúdio para uma história: ciência e tecnologia no Brasil. Ed. Universidade de São Paulo, São Paulo, $518 \mathrm{p}$.

Nogueira, E. N. 2000. Uma história brasileira da botânica. Paralelo 15, São Paulo, 255p.

Rodrigues, J. B. 1998. O Jardim Botânico do Rio de Janeiro: Uma lembrança do $1^{\circ}$ centenário. Rio de Janeiro. Instituto de Pesqui- 
sas Jardim Botânico do Rio de Janeiro. Edição fac-similar da obra de 1908, 44p. 1905. A Botânica: nomenclatura indígena e seringueiras. Rio de Janeiro, Jardim Botânico do Rio de Janeiro, 86p. 1998. Hortus Fluminensis. Rio de Janeiro: Expressão e Cultura, 51p. 1879. Protesto-apêndice in Sertum Palmarum. Typografia Nacional, Rio de Janeiro, 54p.

Sá, M. R. 2001. O botânico e o mecenas: João Barbosa Rodrigues e a ciência na segunda metade do século XIX. História, Ciências, Saúde: Manguinhos. 7(Supl.): 899-924.

Schwarcz, L. M. 1993. O espetáculo das raças: cientistas, instituições e a questão racial no Brasil - 1870-1930. São Paulo, Cia. das Letras, 287p.

Stumpf, I. R. C. 1998. Reflexões sobre as revistas brasileiras. Revista eletrônica Intexto Programa de pós-graduação, PPGCOM, n. 3. Capturado na internet em 05/07/2005 http://www.intexto.ufrgs.br/v1n3/av1n3a3.html 1996. Passado e futuro das revistas científicas. Ciência da Informação, 25(3). Capturado na internet em 5/07/2005. http:/ /www.ibict.br/cienciadainformacao/include/ getdoc.php?id=846\&article $=504 \&$ mode $=$ pdf.

Ziman, J. 1979. Comunidade e comunicação. In: Em conhecimento público. São Paulo, EDUSP, Belo Horizonte/Itatiaia, p. 115-38. 
